\title{
Tuberculin reactivity in a population of schoolchildren with high BCG vaccination coverage
}

\author{
Ana L. Bierrenbach, ${ }^{1}$ Sérgio S. Cunha, ${ }^{1}$ Maurício L. Barreto, ${ }^{2}$ \\ Susan M. Pereira, ${ }^{2}$ Inês Dourado, ${ }^{2}$ Maria Y. Ichihara, ${ }^{1,3}$ \\ Silvana C. Brito, ${ }^{2}$ and Laura C. Rodrigues ${ }^{1}$
}

ABSTRACT Objective. To investigate the influence of BCG vaccination or revaccination on tuberculin skin test reactivity, in order to guide the correct interpretation of this test in a setting of high neonatal BCG vaccination coverage and an increasing BCG revaccination coverage at school age. Methods. We conducted tuberculin skin testing and BCG scar reading in 1148 children aged 7-14 years old in the city of Salvador, Bahia, Brazil. We measured the positive effect of the presence of one or two BCG scars on the proportion of tuberculin skin test results above different cut-off levels (induration sizes of $\geq 5 \mathrm{~mm}, \geq 10 \mathrm{~mm}$, and $\geq 15 \mathrm{~mm}$ ) and also using several ranges of induration size $(0,1-4,5-9,10-14$, and $\geq 15 \mathrm{~mm})$. We also measured the effects that age, gender, and the school where the child was enrolled had on these proportions.

Results. The proportion of tuberculin results $\geq 10 \mathrm{~mm}$ was $14.2 \%$ (95\% confidence interval $(C I)=8.0 \%-20.3 \%)$ for children with no BCG scar, $21.3 \%(95 \% C I=18.5 \%-24.1 \%)$ for children with one BCG scar, and $45.0 \%(95 \% \mathrm{CI}=32.0 \%-58.0 \%)$ for children with two BCG scars. There was evidence for an increasing positive effect of the presence of one and two BCG scars on the proportion of results $\geq 5 \mathrm{~mm}$ and $\geq 10 \mathrm{~mm}$. Similarly, there was evidence for an increasing positive effect of the presence of one and two scars on the proportion of tuberculin skin test results in the ranges of 5-9 $\mathrm{mm}$ and of 10-14 $\mathrm{mm}$. The BCG scar effect on the proportion of results $\geq 5 \mathrm{~mm}$ and $\geq 10 \mathrm{~mm}$ did not vary with age. There was no evidence for $B C G$ effect on the results $\geq 15 \mathrm{~mm}$.

Conclusions. In Brazilian schoolchildren, BCG-induced tuberculin reactivity is indistinguishable, for results under $15 \mathrm{~mm}$, from reactivity induced by Mycobacterium tuberculosis infection. BCG revaccination at school age increases the degree of BCG-induced tuberculin reactivity found among schoolchildren. This information should be taken into account in tuberculin skin test surveys intended to estimate M. tuberculosis prevalence or to assess transmission patterns as well as in tuberculin skin testing of individuals used as an auxiliary tool in diagnosing tuberculosis. Taking this information into consideration is especially important when there is increasing BCG revaccination coverage.

Key words Tuberculosis, BCG vaccine, tuberculin test, immunization programs, Brazil.

1 London University, London School of Hygiene and Tropical Medicine, London, United Kingdom. Send correspondence to: Ana L. Bierrenbach, Infectious Disease Epidemiology Unit, Department of Infectious and Tropical Diseases, London School of Hygiene and Tropical Medicine, Keppel Street, London WC1E 7HT, United Kingdom; telephone:
(44) 0207 9272144; fax: (44) 0207 4364230; e-mail: ana.bierrenbach@lshtm.ac.uk

2 Universidade Federal da Bahia, Instituto de Saúde Coletiva, Salvador, Bahia, Brazil.

3 Coordenação Regional da Fundação Nacional de Saúde, Salvador, Bahia, Brazil.
The tuberculin skin test (TST) remains at present the only routinely available method for the diagnosis of Mycobacterium tuberculosis infection. It is used to decide whether or not to 
administer preventive chemotherapy and also as an auxiliary for diagnosis of tuberculosis disease in infants and young children (1). TST surveys are used to monitor M. tuberculosis infection in a community in order to plan the activities of tuberculosis control programs, by identifying areas of high prevalence of infection and revealing potential cases. Periodic surveys in selected areas are used to estimate the annual risk of $M$. tuberculosis infection. This annual risk has been considered a useful epidemiological index for monitoring the effectiveness of control programs by providing indicators of trends $(2,3)$. However, in addition to the well-known technical difficulties associated with performing the TST, there are also interpretational difficulties associated with its high crosssensitivity with antigens of the BCG vaccine and environmental mycobacteria, and with its loss of sensitivity over time $(4,5)$.

Tuberculosis is the cause of more deaths globally than any other single infectious disease (2). Approximately one-third of the world's population is infected with $M$. tuberculosis, and the World Health Organization (WHO) has estimated that each year there are 8 million new cases and over 1.8 million deaths from the disease (2). In 1998, Brazil ranked 13th among the countries of the world in terms of the tuberculosis burden, even though notification rates had declined from 70 per 100000 population to 50 per 100000 over the preceding two decades (6).

The Ministry of Health in Brazil has a well-run National Tuberculosis Program (NTP). The NTP is responsible for coordinating the surveillance system, establishing standards, and defining guidelines for tuberculosis control (6). However, Brazil is a federation of states, with a decentralized structure for its health system. Therefore, the recommendations of the Ministry of Health may or may not be implemented by local health authorities. Up to 1994 the Brazilian NTP followed the WHO recommendation of administering BCG only once at birth or on first contact with health services. In early 1994 the Brazilian NTP made a new recommendation, that a second dose be administered nationwide at school age, with the aim of adding to or restoring the waning protection imparted by the first dose $(7,8)$. In 1995 a joint statement from the WHO's Global Tuberculosis Programme and Global Programme on Vaccines recommended against repeated BCG vaccination, based on the argument that there was a lack of evidence as to whether repeated doses offered additional protection (9). In 1996, given the gap in knowledge and the opportunity created by the fact that not all Brazilian states had implemented the national recommendation, a large randomized controlled trial started in Brazil. This trial is intended to evaluate the impact on tuberculosis of BCG revaccination at school age in two Brazilian cities that are the capitals of their respective states (Salvador in Bahia, and Manaus in Amazonas). A recent publication (10) explains in detail the reasons for, design of, and baseline results of this trial, which is called "BCG-REVAC."

This paper reports the results of a tuberculin survey performed in 1997 in the city of Salvador, in a sample of the BCG-REVAC trial population. The survey was intended to investigate the influence of neonatal BCG vaccination and schoolchild revaccination on tuberculin reactivity, in order to guide the correct interpretation of TST results in a setting of high neonatal BCG vaccination coverage and of increasing BCG revaccination coverage at school age. This information is important if we plan to continue to use this test as an auxiliary tool in the diagnosis of tuberculosis or in the epidemiological estimation of the tuberculosis problem.

Located in the Northeast region of Brazil, the city of Salvador had a population of some 2.2 million at the time of our survey. Salvador has a high prevalence of tuberculosis, low rates of childhood HIV infection, and high BCG vaccination coverage (11). The city's age-specific tuberculosis incidence rate in 1996 was 18.1/100 000 for the age group of 7-10 years and $30.6 / 100000$ for those 11-14 years old (10). In 1994, BCG vaccination started very slowly to be administered at school age in the city of Salvador, for two groups: a) a minority of children who had missed being vaccinated at birth or on first contact with health services and $b$ ) revaccination for the majority of children who had already been vaccinated at birth or on first contact with health services. However, the Health Department of the state of Bahia decided to interrupt this policy in 1995 so that the BCG-REVAC trial could be begun in Salvador.

\section{METHODS}

As part of the recruitment phase of the BCG-REVAC trial in Salvador, two nurses from the Brazilian Ministry of Health trained a team of health care workers to collect data and to inspect BCG scars. Data on each child's name, date of birth, gender, and grade in school were collected from the school registry and recorded on a standardized form. Next, letters were sent to the guardians of all children ages 7 to 14 enrolled in the schools that were participating in the BCG-REVAC trial. The letters offered information on the trial, made clear the guardians' right to deny participation by their children, requested their agreement for the BCG scar reading procedures and also for BCG vaccination (this latter request was only included in the letters for children enrolled in schools where vaccinations were to be done for the trial), and asked the guardians to send their children's vaccination cards to the schools. These letters also asked the guardians to tell, on a standardized form, how many times their children had been vaccinated with BCG (zero, one, or two times) and when those vaccinations had occurred. Children whose guardians refused to grant permission for participation were excluded from the trial. In the school classes, children were asked to confirm the identification data, and they had their right upper arm inspected for a BCG scar or scars, as this is the recommended site of injection of BCG (7). The scar reading was classified as "none" (no scar), "one" (one scar), "two" (two scars), or "other" (which 
included children who did not have a scar reading and children with doubtful readings). The team of health care workers responsible for the scar readings had no access to the information on the vaccination cards or the other information received in response to the letters sent to the guardians.

As part of the TST survey reported on in this article, four schools participating in the BCG-REVAC trial in the city of Salvador were selected based on convenience (logistics, number of children in each school, and the size of our budget). The study population of the TST survey consisted of children aged 7 to 14 years old enrolled in these four schools. The guardians of these children received a second letter, which offered information on the TST survey, made clear their right to deny permission for their children to participate, and asked for their agreement for the TST injections and readings. Children whose parents refused to grant permission to participate were excluded from the TST survey. Two nurses trained according to standardized methods contained in the published guidelines of the International Union of Tuberculosis and Lung Disease (3) applied the tests. The nurses used the standard Mantoux test, which consists of an intradermal injection of a dose of $0.1 \mathrm{~mL}$ (corresponding to two tuberculin units) of a soluble purified protein derivative (PPD) of M. tuberculosis. We used PPD RT23 produced by the Statens Serum Institute (Copenhagen, Denmark). After 48-72 hours, the site of injection was palpated and the transverse diameter of induration was measured with a transparent ruler. In three of the four schools, each child had his or her induration read only once, by one or the other of the two nurses. In one school, 144 children had their indurations read twice, one time each by the two nurses, and with the nurses being blind to each other's readings. The purpose of these double readings was to assess the agreement between the readings by the two nurses.

The guardians of children with tuberculin reactions $\leq 10 \mathrm{~mm}$ received a letter informing them of this result, explaining its implications, and advising them to take their children to be checked at a local tuberculosis reference center. A list of the local tuberculosis centers was attached to each of these letters.

We analyzed the TST survey data using Stata 6 software (Stata Corporation, College Station, Texas, United States of America). We used the kappa statistic to analyze the concordance of the TST double readings. We performed two separate analyses of the TST results: (1) TST results categorized as positive or negative based on the cut-off points of $5 \mathrm{~mm}, 10 \mathrm{~mm}$, and 15 $\mathrm{mm}$ and (2) TST results categorized as $0 \mathrm{~mm}, 1-4 \mathrm{~mm}, 5-9 \mathrm{~mm}, 10-14 \mathrm{~mm}$, and $\geq 15 \mathrm{~mm}$. We used logistic regression to explore the effects of BCG scar status, age, gender, and the school in which each child was enrolled, with these effects expressed as odds ratios. We also used logistic regression to explore the differences between the participants and nonparticipants in terms of BCG scar status, age, gender, and the school in which each child was enrolled. We used ordered logistic regression exclusively to explore the differences between the proportion of children with none, one, or two scars in terms of age, as the BCG scar status variable had three ordered values.

Neither the BCG-REVAC trial nor the TST survey collected data on the presence of acute or chronic illnesses or on the nutritional status of the study population.

\section{RESULTS}

Table 1 shows the number of schoolchildren aged 7-14 years old participat-

TABLE 1. Study population according to BCG scar status, gender, and age group. Salvador, Bahia, Brazil, 1997

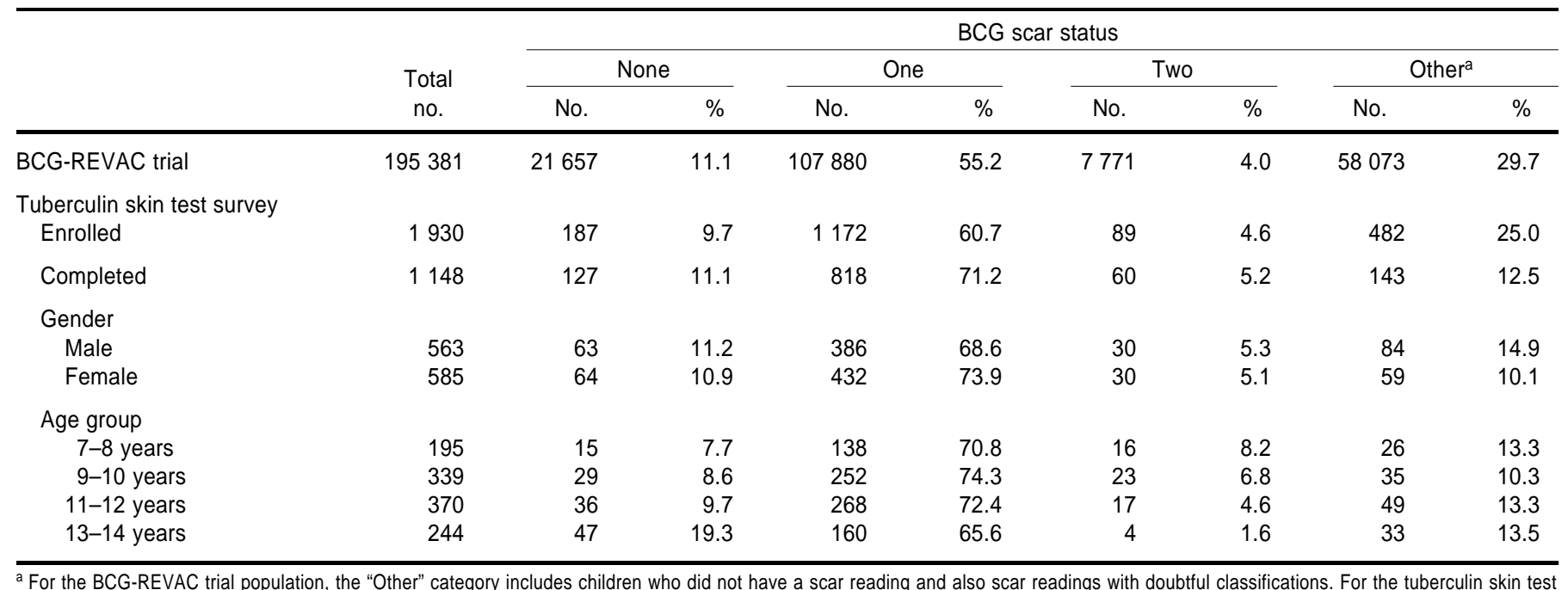

(TST) survey population, this categry inclu 
ing in the BCG-REVAC trial in Salvador, the number of those enrolled in the four schools participating in the TST survey, and the number of those who ultimately completed the TST readings, by BCG scar status. The number of those who ultimately completed the TST readings is also shown separately by age group and gender. The "other" category of BCG scar status included children who did not have a scar reading and also children with doubtful readings. No doubtful readings were recorded among the four schools that participated in the TST survey, and doubtful readings were recorded in just 624 children $(0.3 \%)$ out of the entire BCG-REVAC trial population. There were three main reasons for the low overall participation rate of 1148 out of $1930(59.5 \%)$ in the TST survey: (1) absence from school on the days on which tests were administered or read, (2) children whose guardians refused to allow them to participate, and (3) children who themselves declined to participate.

The participation rate varied according to BCG scar status, age group, gender, and the particular school in which each child was enrolled. Children with scar readings participated more than those for whom scars were not read (69.3\% versus $29.7 \%$, respectively; $P<$ $0.001)$. The age groups also differed in their participation rate; it was $49.6 \%$ for those $7-8$ years old, $61.1 \%$ for those 9-10, 66.2\% for those $11-12$, and $57.7 \%$ for those 13-14 $(P=0.03)$. Excluding those with no scar reading results, females participated more than males (62.3\% versus $56.8 \%, P=0.039)$. Depending on the school, the participation rate ranged from $50.5 \%$ to $65.6 \%$ $(P=0.033)$.

The proportion of children with none, one, and two scars varied with age (Table 1). There was a higher proportion of children with one or two scars among the younger age groups, reflecting an increase in the vaccination coverage over the last decade $(P<$ 0.001).

Out of the 1148 children who participated in the TST survey, the guardians of only 98 of them returned letters with valid information on their chil- dren's BCG vaccination status. Of these 98, 93 reported one vaccination and 5 reported two vaccinations. Using the information on dates of vaccination provided by the letters, we found that 85 of the 98 children $(86.7 \%)$ had received their first dose of BCG in their first year of life, that is, some 7 to 14 years before our survey. Vaccinations that occurred within 2 years of our tuberculin survey were reported in 2 out of 93 children with one reported dose $(2.2 \%)$ and in 4 out of 5 children with two reported doses $(80.0 \%)$.

With respect to the results for the 144 TST double readings that were done, if we consider as concordant the readings with a difference of up to 1 $\mathrm{mm}$, the agreement between the double readings was $97.2 \%$ (kappa $=0.96$, $P<0.001)$. There were 71 double readings in which both results were zero. If we exclude those 71 , the agreement for the remaining 73 double readings was $95.9 \%$ (kappa $=0.95 ; P<0.001)$. These results show an excellent agreement beyond the level of chance and thus indicate a high internal validity of our TST procedures.

Figure 1 shows, for each of the four BCG scar statuses in our survey, the frequency distribution of the size of the TST indurations. This figure shows that the proportion of children with a reading of $0 \mathrm{~mm}$ decreases with number of scars. The frequency distributions are similar if we compare the children with one scar and those for whom scars were not read. There is no clear mode or antimode for results $\geq 1$ $\mathrm{mm}$, except for those with two scars, who had a mode of $10 \mathrm{~mm}$.

Table 2 shows the TST results by ranges of induration sizes and BCG scar status. In addition, the last column of Table 2 shows the "BCG effect" on each range of induration sizes, that is, the odds ratio for the effect of a one-unit increase in the number of scars, according to logistic regression estimates. There was evidence that the proportions of children in the ranges of $0 \mathrm{~mm}, 5-9 \mathrm{~mm}$, and $10-14 \mathrm{~mm}$ were influenced by BCG scar status. The proportion with $0-\mathrm{mm}$ indurations decreased as the number of scars increased. In contrast, the proportion with indurations of 5-9 $\mathrm{mm}$ and of
10-14 $\mathrm{mm}$ increased as the number of scars increased.

Table 3 presents the proportion of positive TST results by BCG scar status. As explained above, the proportion of positive results was defined using three different cut-off points for induration size: $5 \mathrm{~mm}, 10 \mathrm{~mm}$, and 15 $\mathrm{mm}$. There was evidence that the proportions above the cut-offs of $5 \mathrm{~mm}$ and $10 \mathrm{~mm}$, but not $15 \mathrm{~mm}$, were positively influenced by prior BCG scar status.

When we controlled for the BCG effect, the proportion of TST results above each of the cut-offs increased with age (all with $P<0.05$ ). There was some indication that the increase with age of TST results $\geq 10 \mathrm{~mm}$ was different depending on BCG scar status, but the modification effect was not statistically significant $(P=0.22)$. For children with one BCG scar the TST results $\geq 10 \mathrm{~mm}$ were $14.5 \%, 19.8 \%$, $21.6 \%$, and $28.8 \%$ for the groups of $7-8$, 9-10, 11-12, and 13-14 years, respectively $(P<0.001)$. However, for children with no scar, the age trend was less clear, with the TST results being $6.7 \%, 13.8 \%, 5.6 \%$, and $23.4 \%$ for those same age groups $(P=0.09)$. There was also no evidence that BCG scar modified the effect of age on TST $\geq 5,10$ and $15 \mathrm{~mm}$, or on TST in any of the induration ranges (all with $P>0.52$, data not shown).

There was no difference by gender or school in the proportion of children above any of the TST cut-offs (data not shown). There was no evidence that gender modified the effect of age or the BCG effect on TST $\geq 10 \mathrm{~mm}$ or on TST above any other cut-off point or in any of the induration ranges (data not shown).

\section{DISCUSSION}

There were four main findings from our TST survey. First, the proportion of TST results above $10 \mathrm{~mm}$ was $14.2 \%$ $(95 \%$ CI $=8.0 \%-20.3 \%)$ for children with no BCG scar, $21.3 \%$ ( $95 \%$ CI = $18.5 \%-24.1 \%)$ for children with one BCG scar, and $45.0 \%$ (95\% CI $=32.0 \%-$ $58.0 \%$ ) for children with two BCG 
FIGURE 1. Frequency distribution of tuberculin indurations (size in $\mathrm{mm}$ ) among school children aged 7-14 years, by BCG scar status. Salvador, Bahia, Brazil, 1997

h.

Ho $\cos =0$

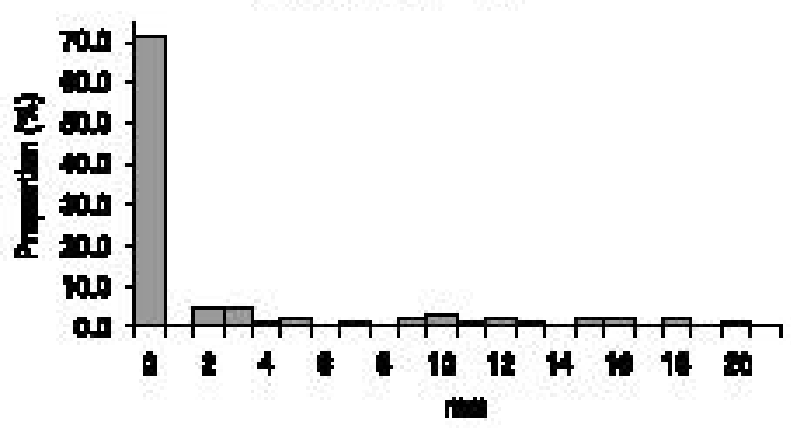

C.

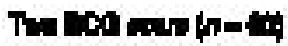

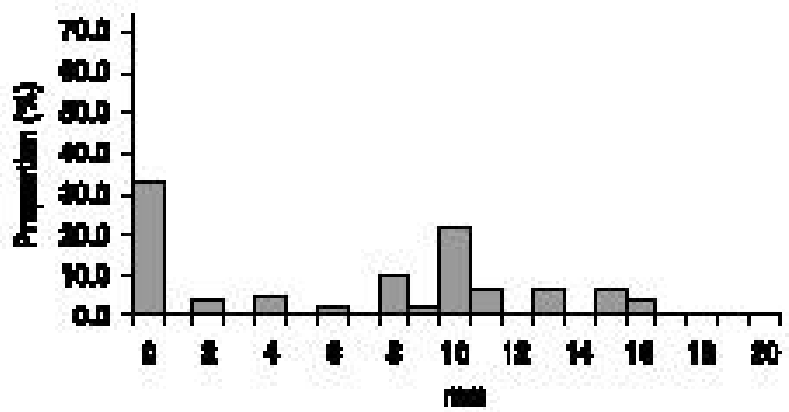

$\mathbf{2}$

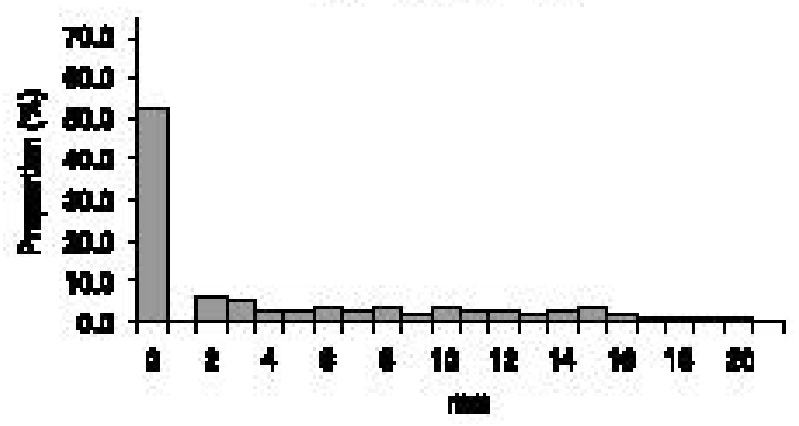

D.

con morntme in= 14h

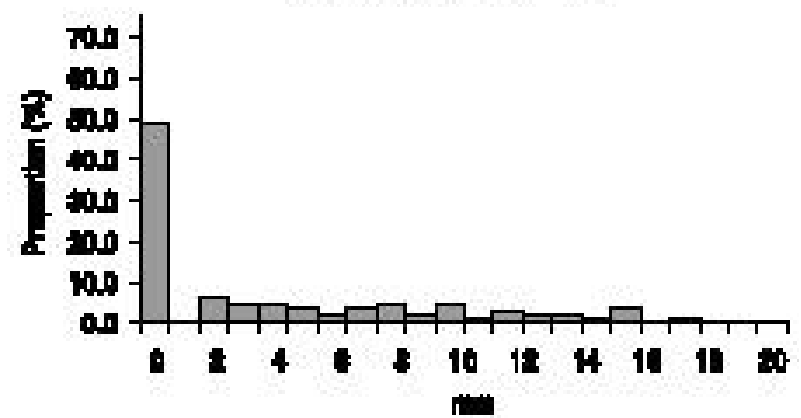

TABLE 2. Distribution of tuberculin skin test results by ranges of induration sizes and BCG scar status, and estimates of the BCG effect on each range of induration sizes. Salvador, Bahia, Brazil, 1997

\begin{tabular}{|c|c|c|c|c|c|c|c|c|}
\hline \multirow{3}{*}{$\begin{array}{l}\text { Induration size } \\
(\mathrm{mm}) / \text { Total }\end{array}$} & \multicolumn{6}{|c|}{ BCG scar status } & & \\
\hline & \multicolumn{2}{|c|}{ None } & \multicolumn{2}{|c|}{ One } & \multicolumn{2}{|c|}{ Two } & \multicolumn{2}{|c|}{ BCG effect ${ }^{2}$} \\
\hline & No. & $\%$ & No. & $\%$ & No. & $\%$ & Odds ratio & $95 \% \mathrm{Cl}^{\mathrm{b}}$ \\
\hline 0 & 91 & 71.7 & 429 & 52.4 & 20 & 33.4 & 0.6 & $0.4-0.7$ \\
\hline $1-4$ & 13 & 10.2 & 110 & 13.5 & 5 & 8.3 & 1.0 & $0.7-1.6$ \\
\hline $5-9$ & 5 & 3.9 & 105 & 12.8 & 8 & 13.3 & 1.8 & $1.1-2.8$ \\
\hline $10-14$ & 9 & 7.1 & 111 & 13.6 & 21 & 35.0 & 3.0 & $1.9-4.4$ \\
\hline 15 & 9 & 7.1 & 63 & 7.7 & 6 & 10.0 & 1.4 & $0.8-2.7$ \\
\hline Total & 127 & 100.0 & 818 & 100.0 & 60 & 100.0 & $N A^{c}$ & NA \\
\hline
\end{tabular}

a BCG effect shows the odds ratio for the effect of one unit increase in the number of scars, according to logistic regression estimates.

b $95 \% \mathrm{Cl}=95 \%$ confidence interval.

c NA = not applicable.

scars. Second, there was evidence for an increasing positive effect of number of BCG scars on the proportion of TST results above the cut-offs of $5 \mathrm{~mm}$ and $10 \mathrm{~mm}$ and also on the proportion of TST results in the ranges of 5-9 $\mathrm{mm}$ and $10-14 \mathrm{~mm}$. Third, the BCG scar ef- fect on the proportion of TST results above the cut-offs of $5 \mathrm{~mm}$ and $10 \mathrm{~mm}$ did not vary with age. Finally, there was no evidence for BCG effect on the results above the cut-off of $15 \mathrm{~mm}$.

Measuring the proportion of tuberculin skin test results of $10 \mathrm{~mm}$ or larger is one of the recommended ways to estimate the prevalence of $M$. tuberculosis infection in unvaccinated children $(3,12,13)$. However, we believe that the results presented in this survey do not adequately estimate the prevalence of $M$. tuberculosis infec- 
TABLE 3. Proportion of positive tuberculin skin test results, using three different cut-off points, by BCG scar status, Salvador, Bahia, Brazil, 1997 ${ }^{a}$

\begin{tabular}{|c|c|c|c|c|c|c|c|c|}
\hline \multirow{4}{*}{$\begin{array}{c}\text { Cut-off } \\
\text { point }\end{array}$} & \multicolumn{6}{|c|}{ BCG scar status } & & \\
\hline & \multicolumn{2}{|c|}{$\begin{array}{c}\text { None } \\
(n=127)\end{array}$} & \multicolumn{2}{|c|}{$\begin{array}{c}\text { One } \\
(n=818)\end{array}$} & \multicolumn{2}{|c|}{$\begin{array}{c}\text { Two } \\
(n=60)\end{array}$} & \multirow{2}{*}{\multicolumn{2}{|c|}{$B C G$ effect $^{b}$}} \\
\hline & $\%$ & & $\%$ & & $\%$ & & & \\
\hline & positive $^{c}$ & $95 \% \mathrm{Cl}^{\mathrm{c}}$ & positive $^{c}$ & $95 \% \mathrm{Cl}^{\mathrm{c}}$ & positive $^{c}$ & $95 \% \mathrm{Cl}^{\mathrm{c}}$ & Odds ratio & $95 \% \mathrm{Cl}^{\mathrm{d}}$ \\
\hline $5 \mathrm{~mm}$ & 18.1 & $11.3-24.9$ & 34.1 & $30.9-37.4$ & 58.3 & $45.5-71.2$ & 2.7 & $1.9-3.8$ \\
\hline $10 \mathrm{~mm}$ & 14.2 & $8.0-20.3$ & 21.3 & $18.5-24.1$ & 45.0 & $32.0-58.0$ & 2.5 & $1.7-3.7$ \\
\hline $15 \mathrm{~mm}$ & 7.1 & $2.6-11.6$ & 7.7 & $5.9-9.5$ & 10.0 & $2.2-17.8$ & 1.4 & $0.8-2.4$ \\
\hline
\end{tabular}

\footnotetext{
a Positive results are defined as those above the induration sizes of $5 \mathrm{~mm}, 10 \mathrm{~mm}$, and $15 \mathrm{~mm}$. Estimates of the BCG effect are given for the proportion of positive results above each of these cut-offs.

${ }^{b}$ BCG effect $=$ odds ratio for the effect of one unit increase in the number of scars, according to logistic regression estimates.

C The denominators used for calculating the proportion of positive results are the numbers 127,818 and 60 for children with respectively none, one and two BCG scars. The numerators used for these calculations are the numbers of positive results, which were defined using three different cut-offs of induration sizes $(5 \mathrm{~mm}, 10 \mathrm{~mm}$, and $15 \mathrm{~mm}$ ).

d $95 \% \mathrm{Cl}=95 \%$ confidence interval.
}

tion in unvaccinated schoolchildren aged 7-14 years, for several reasons. First, our TST survey study population does not represent the entire population of schoolchildren aged 7-14 years, as logistics and budget size determined the selection of a convenience sample of the schools. Second, children with no scar in the TST survey do not represent the entire population of schoolchildren aged 7-14 years, given the high BCG vaccination coverage of schoolchildren aged 7-14 years (14). Children with no scar participating in the TST survey also do not represent the entire population of the TST survey. Third, the shape of the frequency distribution of our TST results did not show a clear antimode that could have been used to logically choose a cut-off point that would differentiate between infected and uninfected individuals $(12,15)$. We did not have any other way to determine how many of the TST children in each of the induration sizes or above each of the cut-offs would represent true $M$. tuberculosis infection and not cross-reactions with environmental mycobacteria. We do have unpublished data from a small dual skin test survey performed by our group in the city of Salvador in which each child was tested with one injection of tuberculin (PPD derived from M. tuberculosis) and with one injection of one of the two sensitins
(PPD derived from $M$. scrofulaceum or $M$. kansasii, two environmental species of the genus mycobacteria). This dual skin test survey showed that many schoolchildren living in Salvador have been sensitized by these antigens.

It is unlikely that our results have been affected in any significant way by misclassification of TST readings, by misclassification of BCG scar readings, or by misclassification of vaccination status obtained from using the presence of BCG scars as a single marker. We demonstrated the high internal validity of the TST results with the high concordance between the TST double readings performed by our two study nurses. We demonstrated high internal and external validity of the BCG scar readings in the city of Salvador in another recently published study performed with data from the entire BCGREVAC trial population in this city (14).

Information on the dates of vaccination was obtained for only a small number of children participating in the TST survey and just a small proportion of children participating in the BCG-REVAC trial (14). Nevertheless, we believe both of those sources of information are representative of the entire population of schoolchildren aged 7 to 14 years. According to data from the Brazilian Ministry of Health, most children in Brazil receive the first dose of BCG during the first year of life. As explained earlier in this article, revaccination only became a national recommendation in 1994, that is, 3 years before this survey in Salvador (7). The Department of Health of the state of Bahia had just started to implement the revaccination policy in Salvador when the Department decided to interrupt it, so that the BCG-REVAC trial could be initiated in the city.

It is well known that BCG induces TST reactivity, especially in the short term. For some populations skin tested on two occasions after vaccination the BCG-induced TST reactivity seems to remain practically unchanged for many years (16). However, for other populations it appears to wane, particularly for those whose first TST was done shortly after vaccination (17-26). This waning may explain the findings of the relatively low reactivity $(14.5 \%$ using the cut-off of $10 \mathrm{~mm}$ ) among children with one BCG scar in the youngest age group (7-8 years), which agrees with the findings from a study in the country of Malawi (26). The magnitude of the BCG-induced TST sensitivity seems to vary among individuals and communities, but it is usually of an intermediate size. The more stringent the criteria are for considering a TST reaction to be positive, the less the influence of BCG vaccination seems to be. Our study agrees with the 
positive influence of BCG on tuberculin reactivity of $\geq 10 \mathrm{~mm}$ found by some studies (26-31) but differs from other studies (32-36). It also agrees with the findings of an absence of the BCG effect on tuberculin reactivity of a more stringent criterion ( $15 \mathrm{~mm}$ in our study) as reported in a few studies (26, 37) but disagrees with another study (29). Our finding of a constant BCG effect from 7 to 14 years on TST results of $\geq 5 \mathrm{~mm}$ and $\geq 10 \mathrm{~mm}$ has also been shown in a detailed study in Malawi that included individuals of all ages (26). That is, only a minority of our schoolchildren vaccinated as neonates or infants have tuberculin reactivity that can be attributable to BCG, but for those who do have that reactivity, it seems to last at least up to their early adolescence $(24,26)$.

Studies that describe tuberculin reactivity after BCG vaccination have methodological differences in relation to vaccine strain and dose, vaccination schedule and coverage, tuberculin strain and dose, and time elapsed since vaccination. However, analyzed separately, these differences do not explain the variations in the proportion of BCG-induced tuberculin reactivity above different cut-offs. The complexities of this subject can be exemplified with one recent review that emphasized the importance of age at vaccination (38). It is possible that age at vaccination explains some of the above-mentioned variations found in different settings. If vaccination is administered at birth, BCG-induced reactions tend to be smaller and to wane more rapidly than if vaccination is administered later in life $(16,39)$. This is believed to be related to the "maturation" of the immune system (40). However, age at vaccinations alone cannot explain the differences found in regions or countries that use similar vaccination and TST procedures. Exposure to environmental mycobacteria or other immunological cross-experiences as well as genetic factors may also play important and perhaps concomitant roles $(26,41-43)$.

Another possibility is that differences in the BCG vaccine strains and/ or in the methods of BCG culture employed by the various manufacturers may also influence the vaccine's capacity to induce persistent TST reactivity (26). A recent genomic study has provided a detailed description of the differences found among the many BCG strains (44). Comparative studies in mice and in humans could distinguish between the different TST reactogenicities induced by different strains, and three of these comparative studies indicated that the Moreau (Rio de Janeiro) strain showed a tendency for stronger reactogenicity (45-47). The Moreau (Rio de Janeiro) strain is used throughout Brazil.

We found evidence that the presence of two BCG scars induced higher tuberculin reactivity than did the presence of only one scar, which agrees with results from one study in $\mathrm{Ku}$ wait (48) and one in Turkey (49). This may be due to the fact that the great majority of the second vaccinations probably occurred within 2 years of our survey. BCG revaccination in Brazil was not an accepted policy until 1994, and that revaccination only started in the city of Salvador later in that year, while this survey was done in the beginning of 1997. Alternatively, there may be a real cumulative effect of repeated vaccination on TST reactivity. In our study, it was not possible to separate any effects of age of vaccination and interval since vaccination from the effect of the number of vaccinations.

We believe that the patterns of the BCG-vaccination-induced and BCGrevaccination-induced tuberculin reactivity presented in this survey could be generalized to schoolchildren of 7-14 years in the city of Salvador and could even be generalized to schoolchildren in other Brazilian cities. These are not novel aspects in the world scientific literature, but we wanted to have a local picture, given the variety of results found in different settings.

In summary, in interpreting TST results in Brazilian schoolchildren one must take into account that BCGinduced tuberculin reactivity is indistinguishable, for results under $15 \mathrm{~mm}$, from reactivity induced by $M$. tuberculosis infection. BCG revaccination at school age increases the degree of BCG-induced tuberculin reactivity found among schoolchildren. This information should be kept in mind in tuberculin skin test surveys intended to estimate the prevalence of infection by $M$. tuberculosis or to assess transmission trends as well as in tuberculin skin testing of individuals used as an auxiliary tool in diagnosing tuberculosis. This is especially important when there is increasing BCG revaccination coverage.

Acknowledgments. This survey was supported financially by the Brazilian BCG-REVAC trial. This trial is supported by grants from the Department of International Development of the United Kingdom and from the $\mathrm{Na}-$ tional Health Foundation of Brazil. Coauthor Ana L. Bierrenbach received a fellowship from CAPES, in Brazil. We would like to thank the Health and Education departments of the state of Bahia. We acknowledge the invaluable contribution by the study nurses Raimunda Maria Campos dos Santos and Rosângela Maria Magalhães Vargas. We thank Professor Vanize Oliveira Macêdo and Professor Antonio RuffinoNetto for their support in the early stages of this project. We are most grateful to the children who participated in this study. 


\section{REFERENCES}

1. Lee E, Holzman RS. Evolution and current use of the tuberculin test. Clin Infect Dis 2002; 34:365-370.

2. Dye C, Scheele S, Dolin P, Pathania V, Raviglione MC. Consensus statement. Global burden of tuberculosis: estimated incidence, prevalence, and mortality by country. WHO Global Surveillance and Monitoring Project. JAMA 1999;282(7):677-686.

3. Arnadottir T, Rieder HL, Trebucq A, Waaler HT. Guidelines for conducting tuberculin skin test surveys in high prevalence countries. Tuber Lung Dis 1996;77(suppl 1):1-19.

4. Menzies R, Vissandjee B. Effect of bacille Calmette-Guerin vaccination on tuberculin reactivity. Am Rev Respir Dis 1992;145(3): 621-625.

5. Fine PEM, Floyd S, Stanford JL, As LC, Chaguluka S, Warndorff DK, et al. Environmental mycobacteria in Northern Malawi: implications for the epidemiology of tuberculosis and leprosy. Epidemiol Infection 2001;126:379387.

6. Ruffino-Netto A, de Souza AM. Evolution of the health sector and tuberculosis control in Brazil. Rev Panam Salud Publica 2001;9(5): 306-310

7. Brasil, Ministério da Saúde do Brasil. Segundo informe técnico sobre vacinação/revacinação BCG. Brasília: Ministério da Saúde; 1994.

8. Sterne JA, Rodrigues LC, Guedes IN. Does the efficacy of BCG decline with time since vaccination? Int J Tuberc Lung Dis 1998;2(3):200207.

9. Global Tuberculosis Programme and Global Program on Vaccines. Statement on BCG revaccination for the prevention of tuberculosis. Wkly Epidemiol Rec 1995;70(32):229-231.

10. Barreto ML, Rodrigues LC, Cunha SS, Pereira S, Hijjar MA, Ichihara MY, et al. Design of the Brazilian BCG-REVAC trial against tuberculosis: a large, simple randomized community trial to evaluate the impact on tuberculosis of BCG revaccination at school age. Control Clin Trials 2002;23:540-553.

11. Brasil, Departamento de Informática do Sistema Unico de Saúde. Indicadores e dados básicos de saúde 1998 [Internet site]. Available from: http://www.datasus.gov.br/cgi/idb98/ matriz.htm. Accessed 10 October 2001

12. Rieder HL. Methodological issues in the estimation of the tuberculosis problem from tuberculin surveys. Tuber Lung Dis 1995;76(2): $114-121$

13. Borgdorff MW, Egwaga SM, Muwinge $\mathrm{H}$, Kalisvaart NA, Nagelkerke NJD. Density of tuberculin skin reaction and its association with tuberculosis infection as defined by dual skin testing. Int J Tuber Lung Dis 2000;4(11): 1060-1065.

14. Pereira SM, Dourado MI, Barreto ML, Cunha SS, Ichihara MY, Rodrigues LC. Sensitivity and specificity of BCG scar reading in Brazil. Int J Tuberc Lung Dis 2001;5(11):1067-1070.

15. Neuenschwander BE, Zwahlen M, Kim SJ, Engel RR, Rieder HL. Trends in the prevalence of infection with Mycobacterium tuberculosis in Korea from 1965 to 1995: an analysis of seven surveys by mixture models. Int J Tuber Lung Dis 2000;4:719-729.

16. Horwitz O, Bunch-Christensen K. Correlation between tuberculin sensitivity after 2 months and 5 years among BCG vaccinated subjects. Bull WHO 1972;47:49-58.

17. Baily GV. Tuberculosis prevention trial, Madras. Indian J Med Res 1980;72 Suppl:1-74

18. Dawodu AH. Tuberculin conversion following BCG vaccination in preterm infants. Acta Paediatr Scand 1985;74(4):564-567.

19. Karalliedde S, Katugaha LP, Uragoda CG. Tuberculin response of Sri Lankan children after BCG vaccination at birth. Tubercle 1987;68: 33-38.

20. Sedaghatian MR, Shana'a IA. Evaluation of BCG at birth in the United Arab Emirates. Tubercle 1990;71(3):177-180.

21. Aggarwal A, Dutta AK. Timing and dose of BCG vaccination in infants as assessed by postvaccination tuberculin sensitivity. Indian Pediatr 1995;32(6):635-639.

22. Ferreira AA, Bunn Moreno MM, Sant'Anna CC, Ferreira MF. BCG vaccination in low birth weight newborns: analysis of lymphocyte proliferation, IL-2 generation and intradermal reaction to PPD. Tuber Lung Dis 1996;77(5): $476-481$

23. Hoft DF, Kemp EB, Marinaro M, Cruz O Kiyono H, McGhee JR, et al. A double-blind, placebo-controlled study of Mycobacteriumspecific human immune responses induced by intradermal bacille Calmette-Guerin vaccination. J Lab Clin Med 1999;134(3):244-252.

24. Black GF, Weir RE, Floyd S, Bliss L, Warndorff DK, Crampin AC, et al. BCG-induced increase in interferon-gamma response to mycobacterial antigens and efficacy of BCG vaccination in Malawi and the UK: two randomised controlled studies. Lancet 2002;359(9315): 1393-1401.

25. Aydinlioglu H, Caglayan S, Kansoy S, Yaprak I, Seckin E, Bakiler AR, et al. The decline of BCG immunity after neonatal vaccination: what about revaccination at one year? Paediatr Perinat Epidemiol 1993;7:334-348.

26. Fine PE, Bruce J, Ponnighaus JM, Nkhosa $P$ Harawa A, Vynnycky E. Tuberculin sensitivity: conversions and reversions in a rura African population. Int J Tuberc Lung Dis 1999;3(11):962-975.

27. Gloyd S, Lopez JL, Mercado FJ, Durning J Riesgo de infección por Mycobacterium tuberculosis en Jalisco, México. Bol Oficina Sanit Panam 1991;111(5):393-401.

28. Larsson LO, Magnusson M, Skoogh BE, Lind A. Sensitivity to sensitins and tuberculin in Swedish children. IV. The influence of BCGvaccination. Eur Respir J 1992;5(5):584-586.

29. Miret Cuadras P, Pina Gutierrez JM, Juncosa $\mathrm{S}$. Tuberculin reactivity in Bacillus CalmetteGuerin vaccinated subjects. Tuber Lung Dis 1996;77(1):52-58.

30. Waddell RD, von Reyn CF, Baboo KS, Mwinga A, Chintu C, Zumla A. The effects of BCC immunization and human immunodeficiency virus infection on dual skin test reactions to purified protein derivative and Mycobacterium avium sensitin among adults in Zambia. Int J Tuberc Lung Dis 1999;3(3):255- 260

31. Bierrenbach AL, Cunha SS, Barreto ML, Pereira SM, Rodrigues LC. Skin test reactivity to mycobacterial antigens parallels the phylogenetical structure of their genus. Int J Tuberc Lung Dis 2001;5(7):656-663.

32. Young TK, Mirdad S. Determinants of tuberculin sensitivity in a child population covered by mass BCG vaccination. Tuber Lung Dis 1992;73(2):94-100.

33. Mudido PM, Guwatudde D, Nakakeeto MK, Bukenya GB, Nsamba D, Johnson JL, et al. The effect of bacille Calmette-Guerin vaccination at birth on tuberculin skin test reactivity in Ugandan children. Int J Tuberc Lung Dis 1999;3(10):891-895.

34. Johnson H, Lee B, Doherty E, Kelly E, McDonnell T. Tuberculin sensitivity and the BCC scar in tuberculosis contacts. Tuber Lung Dis 1995;76(2):122-125.

35. Rumisha D, Baratedi J, Chimidza N, Hirschfeld C, Reed M, Notha M, et al. Tuberculin skin test survey in a pediatric population with high BCG vaccination coverage Botswana, 1996. MMWR Morb Mortal Wkly Rep 1997;46(36):846-851.

36. Lockman S, Tappero JW, Kenyon TA, Rumisha D, Huebner RE, Binkin NJ. Tuberculin reactivity in a pediatric population with high BCG vaccination coverage. Int J Tuberc Lung Dis 1999;3(1):23-30.

37. Kuyucu N, Kuyucu S, Bakirtas A, Karacan C. $B C G$ revaccination and tuberculin reactivity. Indian J Pediatr 2001;68:21-25.

38. Menzies D. What does tuberculin reactivity after Bacille Calmette-Guérin vaccination tell us? Clin Inf Dis 2000;31 (suppl 3):71-4.

39. Suciliene E, Ronne T, Plesner AM, Semenaite B, Slapkauskaite D, Larsen SO, et al. Infant BCG vaccination study in Lithuania. Int $\mathrm{J}$ Tuberc Lung Dis 1999;3:956-961.

40. Al Zahrani K, Al Jahdali H, Menzies D. Does size matter? Utility of size of tuberculin reactions for the diagnosis of mycobacterial disease. Am J Respir Crit Care Med 2000;162: 1419-1422.

41. Snider DE Jr. Bacille Calmette Guerin vaccinations and tuberculin skin tests. JAMA 1985 253:3438-3439.

42. Brewer TF, Wilson ME, Nardell EA. BCG immunization: review of past experience, current use, and future prospects. Curr Clin Top Infect Dis 1995;15:253-270.

43. Black GF, Dockrell HM, Crampin AC, Floyd $\mathrm{S}$, Weir RE, Bliss L, et al. Patterns and implications of naturally acquired immune responses to environmental and tuberculous mycobacterial antigens in northern Malawi. J Infect Dis 2001;184(3):322-329.

44. Behr MA, Small PM. A historical and molecular phylogeny of BCG strains. Vaccine 1999; 17(7-8):915-922.

45. Vallishayee RS, Shashidhara AN, BunchChristensen K, Guld J. Tuberculin sensitivity and skin lesions in children after vaccination with 11 different BCG strains. Bull World Health Organ 1974;51(5):489-494. 
46. Junior LP, Filho PP. Comparative immunogenicity of BCG substrains for mice. Rev Bras Pesqui Med Biol 1979;12(4-5):311-316.

47. Lagranderie MR, Balazuc AM, Deriaud E, Leclerc CD, Gheorghiu M. Comparison of immune responses of mice immunized with five different Mycobacterium bovis BCG vaccine strains. Infect Immun 1996;64(1):1-9.
48. Shaaban MA, Abdul Ati M, Bahr GM, Standford JL, Lockwood DN, McManus IC. Revaccination with BCG: its effects on skin tests in Kuwaiti senior school children. Eur Respir J 1990;3(2):187-191.

49. Ildirim I, Hacimustafaoglu M, Ediz B. Correlation of tuberculin induration with the number of Bacillus Calmette-Guerin vaccines. Pediatr Infect Dis J 1995;14:1060-1063.

Manuscript received 12 June 2002. Revised version accepted for publication 20 February 2003.

RESUMEN Objetivo. Evaluar la influencia de la vacunación o revacunación con BCG sobre la prueba de reactividad a la tuberculina, con el fin de ayudar a la correcta interpretación de esta prueba en lugares con una amplia cobertura neonatal con la vacuna BCG y

Reactividad a la tuberculina en una población escolar con amplia cobertura de vacunación con la BCG una revacunación en edad escolar cada vez más frecuente.

Métodos. Se realizaron la prueba cutánea de la tuberculina y la lectura de la cicatriz de la BCG a 1148 niños de 7 a 14 años de edad de Salvador, Bahía, Brasil. Se evaluó si la presencia de una o dos cicatrices de BCG influía en los resultados de la prueba cutánea de la tuberculina utilizando diferentes puntos de corte (induración $\geq 5 \mathrm{~mm}$, $\geq 10 \mathrm{~mm}$ y $\geq 15 \mathrm{~mm}$ ), y agrupando la induración según su diámetro (0, de 1 a $4 \mathrm{~mm}$, de 5 a $9 \mathrm{~mm}$, de 10 a $14 \mathrm{~mm}$ y $\geq 15 \mathrm{~mm}$ ). También se evaluó si la edad, el sexo o la escuela del niño influyeron sobre los resultados de esta prueba.

Resultados. La induración cutánea provocada por la prueba de la tuberculina resultó $\geq 10 \mathrm{~mm}$ en 14,2\% de los casos (intervalo de confianza de 95\% [IC 95\%]: 8,0 a 20,3\%) en niños sin cicatriz de BCG; $21,3 \%$ (IC 95\%: 18,5 a 24,1\%) en niños con una cicatriz de BCG; y 45,0\% (IC 95\%: 32,0 a 58,0\%) en niños con dos cicatrices de BCG. Se evidenció que la presencia de una o dos cicatrices de BCG aumentó la proporción de resultados $\geq 5 \mathrm{~mm}$ y $\geq 10 \mathrm{~mm}$. Este efecto también se evidenció en la proporción de resultados de las pruebas cutáneas de la tuberculina de 5 a $9 \mathrm{~mm}$ y de 10 a $14 \mathrm{~mm}$ de diámetro. El efecto de las cicatrices de BCG sobre la proporción de resultados $\geq 5 \mathrm{~mm}$ $\mathrm{y} \geq 10 \mathrm{~mm}$ no varió con la edad. No se hallaron indicios de que la vacunación previa con BCG influyera cuando el diámetro resultó $\geq 15 \mathrm{~mm}$.

Conclusiones. En los escolares brasileños, la reactividad tuberculínica inducida por la vacunación con $\mathrm{BCG}<15 \mathrm{~mm}$ no puede distinguirse de la reactividad causada por la infección por Mycobacterium tuberculosis. La revacunación durante la edad escolar aumenta la reactividad tuberculínica provocada por la vacunación inicial. Estos resultados deben tomarse en consideración al utilizar la prueba cutánea de la tuberculina para estimar la prevalencia de $M$. tuberculosis o determinar los patrones de transmisión, así como al emplear esta prueba como herramienta auxiliar en el diagnóstico de la tuberculosis. Estos resultados son de especial importancia frente a la creciente ampliación de la cobertura de la revacunación con BCG. 